Atmos. Chem. Phys., 21, 15619-15630, 2021

https://doi.org/10.5194/acp-21-15619-2021

(C) Author(s) 2021. This work is distributed under

the Creative Commons Attribution 4.0 License.

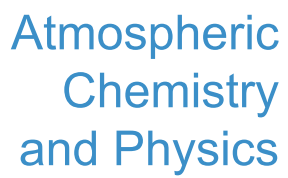

(c) (P)

\title{
Self-consistent global transport of metallic ions with WACCM-X
}

\author{
Jianfei Wu ${ }^{1,2,3}$, Wuhu Feng ${ }^{4,5}$, Han-Li Liu ${ }^{6}$, Xianghui Xue ${ }^{1,2,3,7,8}$, Daniel Robert Marsh ${ }^{6,9}$, and John Maurice \\ Campbell Plane ${ }^{4}$ \\ ${ }^{1}$ CAS Key Laboratory of Geospace Environment, School of Earth and Space Sciences, University of Science and \\ Technology of China, Hefei, China \\ ${ }^{2}$ CAS Center for Excellence in Comparative Planetology, Hefei, China \\ ${ }^{3}$ Mengcheng National Geophysical Observatory, School of Earth and Space Sciences, University of Science and \\ Technology of China, Hefei, China \\ ${ }^{4}$ School of Chemistry, University of Leeds, Leeds, UK \\ ${ }^{5}$ National Center for Atmospheric Science, University of Leeds, Leeds, UK \\ ${ }^{6}$ National Center for Atmospheric Research, Boulder, Colorado, USA \\ ${ }^{7}$ Hefei National Laboratory for the Physical Sciences at the Microscale, University of Science and Technology \\ of China, Hefei, China \\ ${ }^{8}$ Frontiers Science Center for Planetary Exploration and Emerging Technologies, University of Science and \\ Technology of China, Hefei, China \\ ${ }^{9}$ Faculty of Engineering and Physical Sciences, University of Leeds, Leeds, UK
}

Correspondence: Xianghui Xue (xuexh@ustc.edu.cn) and John Maurice Campbell Plane (j.m.c.plane@leeds.ac.uk)

Received: 16 April 2021 - Discussion started: 4 May 2021

Revised: 8 August 2021 - Accepted: 15 September 2021 - Published: 19 October 2021

\begin{abstract}
The NCAR Whole Atmosphere Community Climate Model with thermosphere and ionosphere eXtension (WACCM-X) v2.1 has been extended to include the neutral and ion-molecule chemistry and dynamics of three metals $(\mathrm{Mg}, \mathrm{Na}$, and $\mathrm{Fe})$, which are injected into the upper mesosphere-lower thermosphere by meteoric ablation. Here we focus on the self-consistent electrodynamical transport of metallic ions in both the $\mathrm{E}$ and $\mathrm{F}$ regions. The model with full ion transport significantly improves the simulation of global distribution and seasonal variations of $\mathrm{Mg}^{+}$, although the peak density is slightly lower (about $35 \%$ lower in peak density) compared with the SCIAMACHY measurements. Near the magnetic equator, the diurnal variation in upward and downward transport of $\mathrm{Mg}^{+}$is generally consistent with the "ionosphere fountain effect". The thermospheric distribution of $\mathrm{Fe}$ is shown to be closely coupled to the transport of $\mathrm{Fe}^{+}$. The effect of ion mass on ion transport is also examined: the lighter ions $\left(\mathrm{Mg}^{+}\right.$and $\left.\mathrm{Na}^{+}\right)$are transported above $150 \mathrm{~km}$ more easily than the heavy $\mathrm{Fe}^{+}$. We also examine the impact of the transport of major molecular ions, $\mathrm{NO}^{+}$and $\mathrm{O}_{2}^{+}$, on the distribution of metallic ions.
\end{abstract}

\section{Introduction}

The presence of layers of meteor-ablated metal atoms between 80 and $105 \mathrm{~km}$ has been known for decades (Plane et al., 2015). More recently, there have been a growing number of observations of the thermospheric metal layers up to $200 \mathrm{~km}$. For example, Chu et al. (2011) reported neutral Fe layer observations up to $155 \mathrm{~km}$ at McMurdo, Antarctica $\left(77.8^{\circ} \mathrm{S}, 166.7^{\circ} \mathrm{E}\right)$; Gao et al. (2015) found that several observations of $\mathrm{Na}$ layers reached up to $170 \mathrm{~km}$, using a largeaperture astronomical telescope at Lijiang, China $\left(26.7^{\circ} \mathrm{N}\right.$, $100.0^{\circ} \mathrm{E}$ ); and Friedman et al. (2013) investigated a descending thermospheric $\mathrm{K}$ layer from altitudes above $155 \mathrm{~km}$ at Arecibo, Puerto Rico $\left(18.35^{\circ} \mathrm{N}, 66.75^{\circ} \mathrm{W}\right)$. These highaltitude thermospheric neutral metal layers are challenging to explain, since ablation occurs predominantly below these altitudes, which raises interesting questions regarding their formation mechanisms. Neutral metal atoms and their corresponding atomic ions are tightly coupled through ionization (via photo-ionization or charge transfer with ambient ions, e.g. $\mathrm{NO}^{+}$and $\mathrm{O}_{2}^{+}$) and neutralization (via dielectronic recombination with electrons, or dissociative electron recom- 
bination if they have formed a molecular ion) (Plane et al., 2015). Thus, the vertical and horizontal transport of metallic ions is a key process for controlling the behaviour of neutral atoms in the thermosphere ( $\mathrm{E}$ and $\mathrm{F}$ regions). Interestingly, the reported occurrence of thermospheric metal layers appears to show great geographical variability, underlining the importance of global ion transport. In addition, metallic ions play a central role in the formation of thin, concentrated layers of ions in the E region (sporadic E layers, or Es), which affect radio transmission (e.g. Narcisi, 1968; Layzer, 1972; Plane et al., 2015; Yu et al., 2021).

Thus far, a number of modelling studies have attempted to simulate the transport of metal ions in the thermosphere and, more recently, the role of metallic ions in the formation of the thermospheric metal layers. For example, Carter and Forbes (1999) developed a two-dimensional (2-D) model to examine both global and local transport of $\mathrm{Fe}^{+}$ions; Chu and $\mathrm{Yu}$ (2017) used a thermosphere-ionosphere $\mathrm{Fe} / \mathrm{Fe}^{+}$model to investigate the formation of thermospheric $\mathrm{Fe}$ layers observed by lidar at McMurdo, Antarctica; and Cai et al. (2019) conducted a 2-D simulation of $\mathrm{Na} / \mathrm{Na}^{+}$in the $\mathrm{E}$ and $\mathrm{F}$ regions to explore the formation of thermospheric sodium layers observed at the Andes Lidar Observatory $\left(30.25^{\circ} \mathrm{S}, 70.74^{\circ} \mathrm{W}\right)$. Recently, Huba et al. (2019) have included the global transport of metallic ions $\left(\mathrm{Mg}^{+}\right.$and $\left.\mathrm{Fe}^{+}\right)$in the SAMI3 model of the $\mathrm{E}$ and $\mathrm{F}$ regions and concluded from a $2 \mathrm{~d}$ model run that ions are redistributed by the combined effects of the neutral wind and electric field. However, no previous studies appear to have examined the full transport of metal ions in a selfconsistent global chemical-dynamical model, incorporating the full life cycle of the thermospheric metal atom and metal ion chemistry and the injection of these metals from meteoric ablation.

This paper describes the development of a new global model of three metal species (magnesium, iron, and sodium) in the $\mathrm{E}$ and $\mathrm{F}$ regions, to gain a detailed understanding of the effects of multi-scale atmospheric motions from the lower atmosphere and solar activity on the thermospheric metal layers. The main contribution reported here is to incorporate a self-consistent solution of full global transport of $\mathrm{Mg}^{+}, \mathrm{Fe}^{+}$, and $\mathrm{Na}^{+}$in both the $\mathrm{E}$ and $\mathrm{F}$ regions, within the chemistryclimate WACCM-X 2.1 model (NCAR Whole Atmosphere Community Climate Model with thermosphere and ionosphere eXtension v2.1), in addition to a detailed description of the neutral and ion-molecule chemistry of these metals and the meteoric ablation source required to model the metal atom layers around $90 \mathrm{~km}$. This is described in Sect. 2. Section 3 presents the findings of the model simulation, focusing on the seasonal and the diurnal variation of ions and the effects of ion electrodynamical transport. The final section includes a brief summary and a discussion of future directions with the model.

\section{Model description and ion transport}

\subsection{Model description}

WACCM-X is extended in the present study to include the full life cycle of meteoric metals combined with interactive chemistry, dynamics, deposition, and ion transport in the ionosphere. WACCM-X is an atmospheric component of the Community Earth System Model (CESM, version 2.1.3; Hurrell et al., 2013) developed by the National Center for Atmospheric Research. The key chemistry and dynamical features are based on CAM4 and WACCM4 and are described in detail in Marsh et al. (2013b) and Neale et al. (2013). Validated metal chemistry modules for magnesium (Langowski et al., 2015), sodium (Marsh et al., 2013a), and iron (Feng et al., 2013) with updated rate coefficients from Plane et al. (2015), Bones et al. (2016), and Viehl et al. (2016) are added. The meteoric input functions (MIFs) were estimated from the Leeds Chemical ABLation MODel (CABMOD-3) combined with an astronomical model (Carrillo-Sánchez et al., 2020). The transport of the neutral and ionized metallic species by eddy/molecular diffusion and winds is treated in the same way as the transport of most active chemical species (for example, $\mathrm{O}_{3}$ and $\mathrm{CO}_{2}$ ).

A detailed description of WACCM-X 2.0 is provided by Liu et al. (2018a), and a brief summary is given here. The model has some key features and improvements compared to WACCM-X 1.0 (Liu et al., 2010), including a self-consistent electrodynamics module, F-region $\mathrm{O}^{+}$transport, a solver for electron and ion temperatures, and reduction in the damping coefficient of atmospheric tides (Liu et al., 2018b). The model top is set at $4.1 \times 10^{-10} \mathrm{hPa}(\sim 500$ to $\sim 700 \mathrm{~km}$, depending on solar activity), with a vertical resolution of a quarter of a scale height in the mesosphere and thermosphere. The horizontal resolution is $1.9^{\circ}$ in latitude and $2.5^{\circ}$ in longitude, and all model results used in the paper are from 1-year free-running simulations (perpetual year 2000 AD) under solar medium conditions (constant F10.7 = 130 sfu (solar flux units) and $\mathrm{Kp}=1$ ) with an output frequency of $1 \mathrm{~h}$. The $\mathrm{O}^{+}$ transport method is described in detail by Liu et al. (2018a).

\subsection{Ion transport equation}

Since meteoric ablation, deposition, transport by the neutral winds, eddy and molecular diffusion, chemical production, and loss are already contained in the metal chemistry modules, the metal ion transport is calculated separately, in a similar way to the treatment of $\mathrm{O}^{+}$transport described by Liu et al. (2018a). The continuity equation of metal ion transport can be simplified as

$\frac{\partial n_{\mathrm{i}}}{\partial t}=-\nabla \cdot\left(n_{\mathrm{i}} \boldsymbol{V}_{\mathrm{i}}\right)$,

where $n_{\mathrm{i}}$ represents the number density of metal ions, and $\boldsymbol{V}_{\mathrm{i}}$ is the ion transport velocity. The ion transport velocity is 
adapted from the derivation described by Carter and Forbes (1999) and Chu and Yu (2017), extended to a 3-D global model:

$$
\begin{aligned}
\boldsymbol{V}_{\mathrm{i}}= & \frac{\xi}{1+\xi^{2}} \frac{\boldsymbol{V}_{\mathrm{n}} \times \boldsymbol{B}}{B}+\frac{1}{1+\xi^{2}} \frac{\left(\boldsymbol{V}_{\mathrm{n}} \cdot \boldsymbol{B}\right) \boldsymbol{B}}{B^{2}} \\
& +\frac{\xi}{1+\xi^{2}} \frac{\boldsymbol{E}}{B}+\frac{1}{1+\xi^{2}} \frac{\boldsymbol{E} \times \boldsymbol{B}}{B^{2}}+\boldsymbol{V}_{\mathrm{ambi}}
\end{aligned}
$$

where $\boldsymbol{E}$ and $\boldsymbol{B}$ are the electric field and the Earth's magnetic field, respectively. $\boldsymbol{V}_{\mathrm{n}}$ is the neutral wind, and $\xi=\frac{\nu_{\text {in }}}{\omega_{\mathrm{i}}}$ is the ratio of ion-neutral collision frequency (in the laboratory frame of reference (Banks and Kockarts, 1973) to the ion gyro-frequency. $\boldsymbol{V}_{\text {ambi }}$ is the ion velocity due to ambipolar diffusion, derived from Schunk and Nagy (2000, Eqs. 5.54 and 5.70), where we treat the metallic ions as minor ions and the ion with higher density in $\mathrm{NO}^{+}$and $\mathrm{O}^{+}$as a major ion species. Note that the term corresponding to transport is omitted from Eq. (2) because advection by the neutral wind is already included in the dynamical core of WACCM$X$. The first two terms are related to contributions by the neutral winds, with the first term being the $V \times B$ drift, i.e. the Lorenz force. The third and fourth terms are due to the electric field. A flux-corrected transport (FCT) algorithm (Boris et al., 1993) is applied to compute the vertical transport velocity; this algorithm is designed for solving steep density gradients.

As mentioned above, charge transfer from molecular ions such as $\mathrm{NO}^{+}$and $\mathrm{O}_{2}^{+}$to metal atoms provides a major source of metallic ions. However, due to the short lifetime of these two molecular ions ( $\sim 5 \mathrm{~min}$ in the daytime), they were assumed to be in chemical equilibrium in WACCM-X 2.0. In this study, the transport of molecular ions $\mathrm{NO}^{+}$and $\mathrm{O}_{2}^{+}$is now considered along with the metal ions. Simulation results with and without the molecular ion transport are compared to determine the impact on the metal ion distribution.

\section{Results and discussion}

$\mathrm{Na}^{+}, \mathrm{Fe}^{+}$, and $\mathrm{Mg}^{+}$undergo similar transport forces in the $\mathrm{E}$ and $\mathrm{F}$ regions, apart from the effect of their mass differences. Because $\mathrm{Mg}^{+}$is the only one of these ions for which nearglobal observations are available (Langowski et al., 2015), we focus here on the results for $\mathrm{Mg}^{+}$. However, we also explore $\mathrm{Fe} / \mathrm{Fe}^{+}$ion-neutral coupling in the formation of thermospheric metal layers, since $\mathrm{Fe}$ is the most abundant and widely studied thermospheric metal species. In addition, the $\mathrm{Mg}^{+} / \mathrm{Fe}^{+}$and $\mathrm{Mg}^{+} / \mathrm{Na}^{+}$ratios are employed to examine the effect of metal ion mass difference because $\mathrm{Fe}^{+}$is more than twice as heavy as $\mathrm{Mg}^{+}$(56 versus $24 \mathrm{amu}$ ), while the masses of $\mathrm{Na}^{+}$and $\mathrm{Mg}^{+}$are very similar (23 versus $24 \mathrm{amu}$ ).

\subsection{Seasonal variation of $\mathrm{Mg}^{+}$simulated by WACCM-X}

Figure 1 shows the monthly mean density of $\mathrm{Mg}^{+}$as a function of latitude and altitude, where the monthly mean data are zonally averaged. An obvious seasonal signal is exhibited with clear latitudinal dependence, which is generally consistent with the SCIAMACHY measurements (Fig. 6 in Langowski et al., 2015). Nevertheless, WACCM-X $\mathrm{Mg}^{+}$density is slightly underestimated relative to SCIAMACHY observations (by $\sim 35 \%$ ), which is likely related to the MIF used in the simulation. The peak altitude of $\mathrm{Mg}^{+}$in the summer hemisphere at middle latitudes $\left(\sim 40^{\circ} \pm 10^{\circ}\right)$ is $\sim 10 \mathrm{~km}$ higher than at other latitudes, in accord with observations (Langowski et al., 2015). This appears to be caused by the vertical ion velocity due to the neutral wind (first and second terms in Eq. 2), with the monthly mean drift velocities shown in Fig. 1. Since the metallic ions are the main reservoir for neutral metal atoms in the lower thermosphere (Plane et al., 2015), this is in good agreement with the summer peak occurrence of lower thermospheric neutral Na layers observed by mid-latitude lidars (Wang et al., 2012; Dou et al., 2013; Yuan et al., 2014; Xun et al., 2020).

In contrast to the SCIAMACHY measurements, which show a minimum at the equator, the WACCM-X simulation shows a maximum in peak altitude and number density at the equator. Note that the SCIAMACHY observations are made at a particular local time of around 10:00 LT, whereas the WACCM-X data in Fig. 1 are a diurnal and zonal average. To address this, we also present the simulation results at the same local time (10:00 LT) in Fig. 2, and they are in better agreement with SCIAMACHY observations. Another noteworthy feature is that this simulation shows the pronounced maximum in peak altitude and density at $\sim 45^{\circ}(\mathrm{N} / \mathrm{S})$ at 10:00 LT, in accord with the SCIAMACHY observations, which is absent in WACCM-Mg in Langowski et al. (2015). However, the number densities at 10:00 LT are even lower, and the peak altitude is about $5 \mathrm{~km}$ lower than the daily averaged simulation (Fig. 1). The pronounced discrepancy between Fig. 2 and SCIAMACHY measurements is probably due to the diurnal variation of ion electrodynamical transport, which should be further investigated in the future.

Figure 3a-d present the global geographical distribution of $\mathrm{Mg}^{+}$column densities at the equinoxes and solstices and at 00:00 UTC. The dashed white line depicts the dip equator. Despite the high accumulation of column density at the poles, the $\mathrm{Mg}^{+}$column density exhibits relatively high values at lower and middle latitudes in the summer hemisphere (Fig. $3 b$ and d). This is in good agreement with the conclusion of a summertime maximum shown in Fig. 1. Interestingly, the geographic distributions in all four seasons show stronger convergences along the magnetic equator, which might be related to the modulation of the "equatorial fountain effect". 

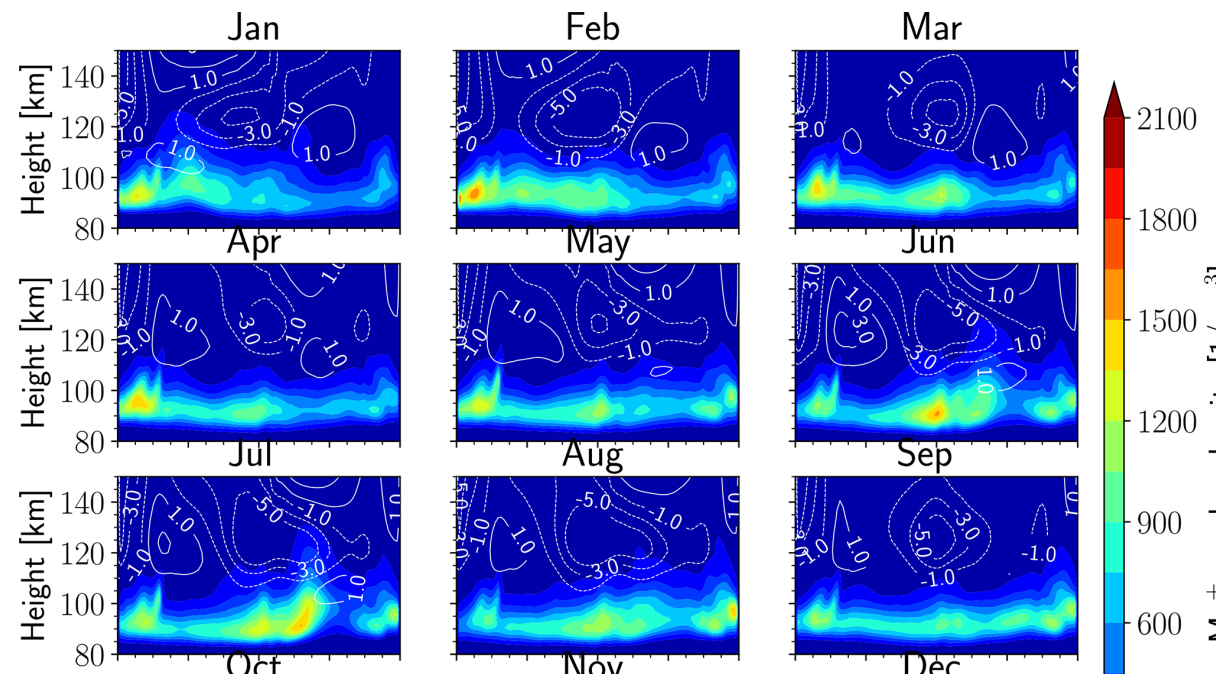

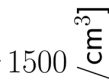

$-1200 \frac{\vec{\nabla}}{\frac{\vec{t}}{\bar{v}}}$

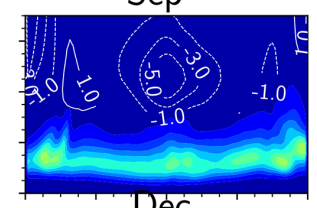

$900 \stackrel{\text { dे }}{\stackrel{\text { है }}{\mathrm{E}}}$

$600{\stackrel{+}{\sum^{\infty}}}^{+\infty}$
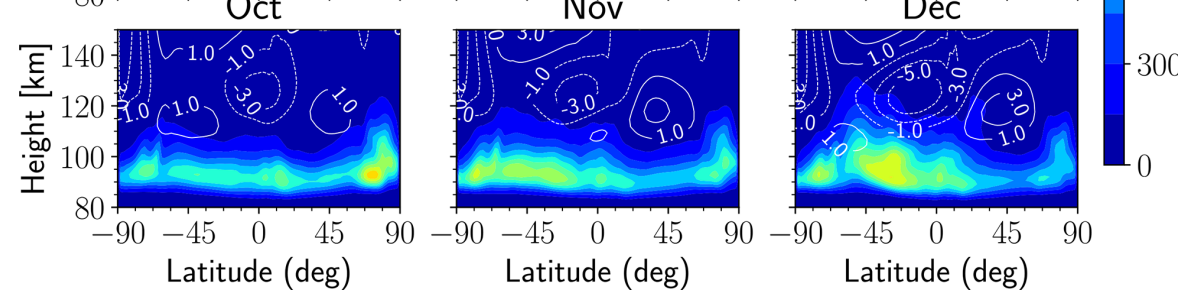

Figure 1. Monthly and zonal mean of the $\mathrm{Mg}^{+}$number density (coloured contours) and the drift velocity (in $\mathrm{m} \mathrm{s}^{-1}$ ) due to the neutral wind (line contours) as a function of latitude and altitude in different months.

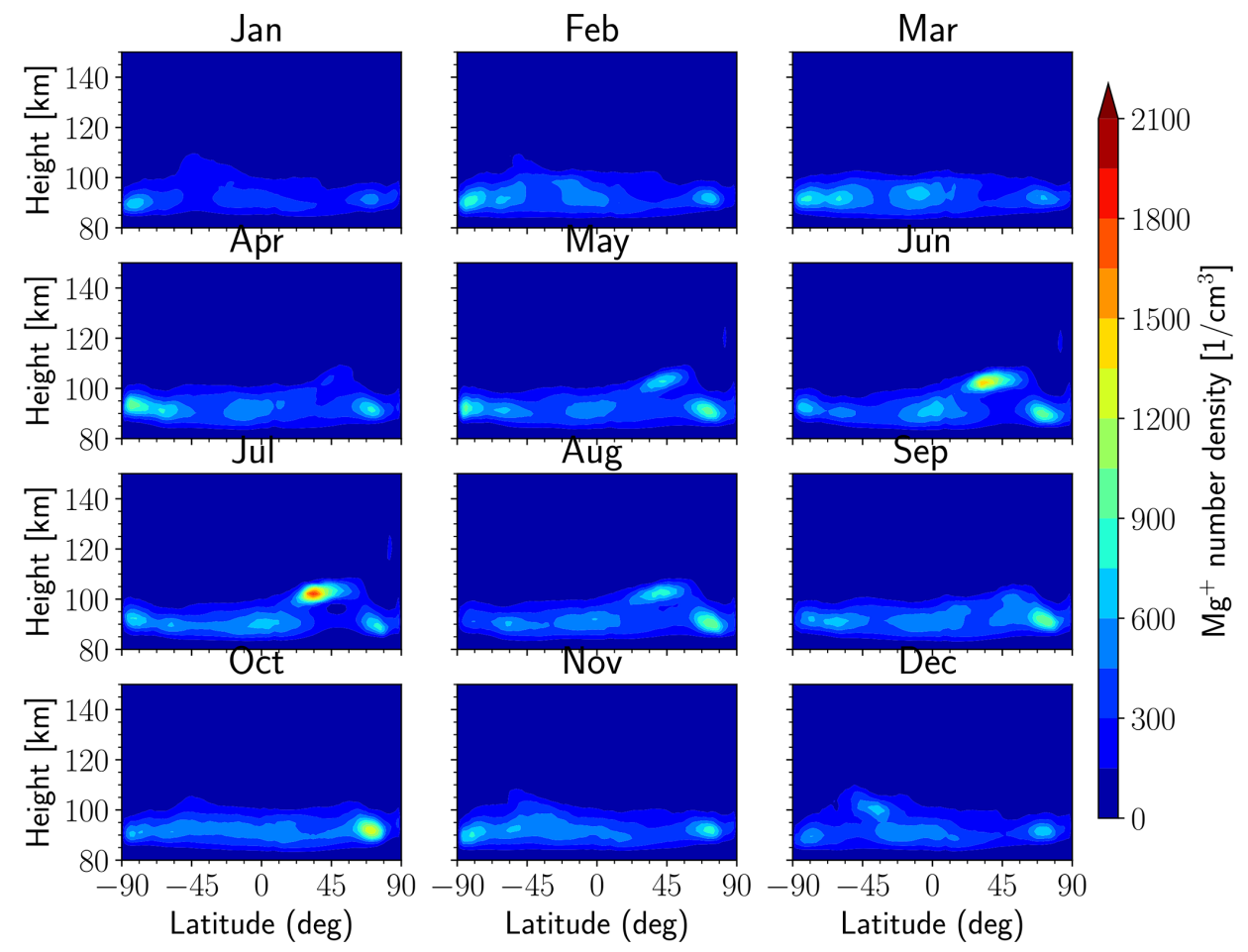

Figure 2. Monthly mean $\mathrm{Mg}^{+}$number density obtained by averaging data at 10:00 LT for all longitudes as a function of latitude and altitude in different months. 
(a) Mar Equinox

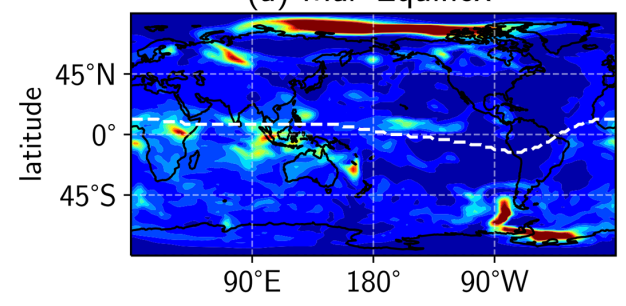

(c) Sep Equinox

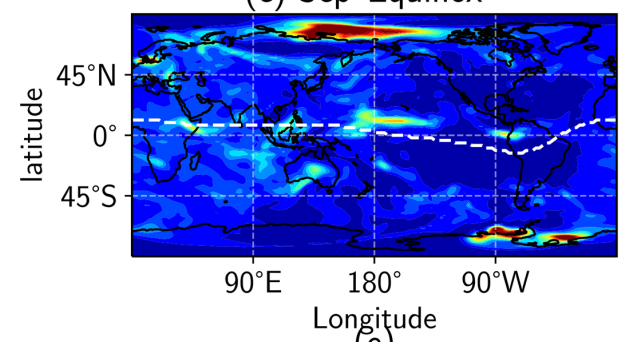

(e)

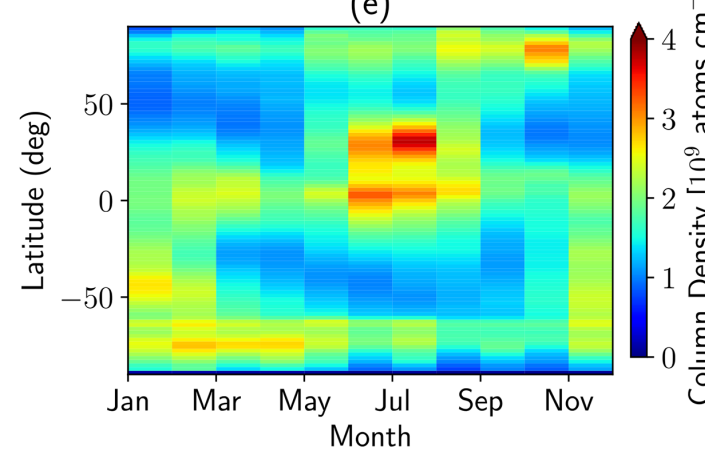

(b) Jun Solstice

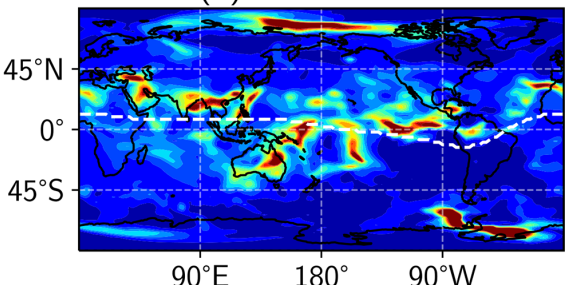

(d) Dec Solstice

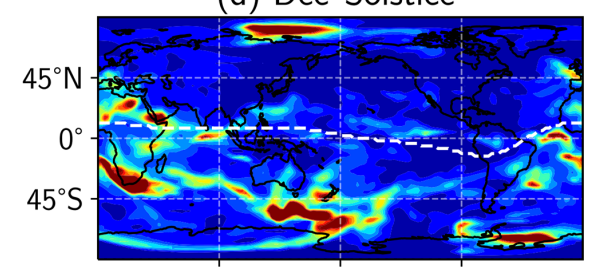

$90^{\circ} \mathrm{E} \quad 180^{\circ} \quad 90^{\circ} \mathrm{W}$

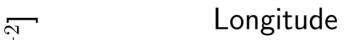

$\begin{array}{llllllll}0.0 & 1.6 & 3.2 & 4.8 & 6.4 & 8.0 & 9.6\end{array}$

Column Density $\left[10^{9}\right.$ atoms $\left.\mathrm{cm}^{-2}\right]$

Figure 3. (a-d) Global geographical distribution of the $\mathrm{Mg}^{+}$column density during the equinoxes and solstices, at 00:00 UTC. (e) Seasonal variation of the zonal mean $\mathrm{Mg}^{+}$column density as a function of month and latitude. The dashed white lines indicates the position of the dip equator.

In Fig. 3e we show the seasonal variation of zonalaveraged $\mathrm{Mg}^{+}$column density at different latitudes. The modelled $\mathrm{Mg}^{+}$column exhibits a maximum in the summer hemisphere at middle and high latitudes, which is in general agreement with the results derived from the SCIAMACHY measurements and WACCM-Mg model results (Figs. 9 and 16 in Langowski et al., 2015) and the SBUV nadir measurements (Fig. 9 in Joiner and Aikin, 1996). The partial column density above $110 \mathrm{~km}$ still shows a similar seasonal variation, which is probably due to thermospheric ion transport (not shown).

\subsection{Diurnal variations of $\mathrm{Mg}^{+}$simulated by WACCM-X}

To investigate the diurnal variation of metallic ions in the model, we present the $\mathrm{Mg}^{+}$number density (on a log scale) as a function of latitude and altitude at the December solstice and $0^{\circ}$ longitude; the panels show universal times (i.e. local times) of 00:00, 06:00, 12:00, and 18:00 UT (Fig. 4a-d). The dotted white line denotes the $\mathrm{F}_{2}$-layer height of the peak electron density $\left(\mathrm{hmF}_{2}\right)$. This shows that the strongest diurnal variations are found in equatorial and high latitudes. Here we focus on the fountain effect on ion transport, where the equatorial ions are first lofted to higher altitudes via $E \times B$ motion and then drift down along the magnetic field lines (Kelley, 2009). $\mathrm{Mg}^{+}$is expected to be lofted to high altitudes ( $\sim 400 \mathrm{~km})$ by the $E \times B$ drift above the magnetic equator during the day because of the daytime eastward electric fields (Huba et al., 2019). Figure $4 \mathrm{e}$ shows the diurnal variation of $\mathrm{Mg}^{+}$number density near the dip equator $\left(12^{\circ} \mathrm{N}, 0^{\circ}\right)$ as a function of local time; the upward drift of $\mathrm{Mg}^{+}$peaks at around 20:00 LT, and the $\mathrm{Mg}^{+}$then drifts down towards the main layer at midnight $(\sim 02: 00 \mathrm{LT})$. Note that the reduction of $\mathrm{Mg}^{+}$at the equator at 06:00 LT confirms that the ion density at the equator is largely dependent on local time (Fig. $4 \mathrm{~b}$ and e). The phase of $\mathrm{Mg}^{+}$diurnal variation shows a high correlation with variations in the electron density (the change of $\mathrm{hmF}_{2}$ ). Instead of being redistributed along the magnetic field lines to the subtropical region by the "classical" fountain effect (e.g. Pi et al., 2009), the $\mathrm{Mg}^{+}$shows a more complex downward trajectory; i.e. the ions are not 


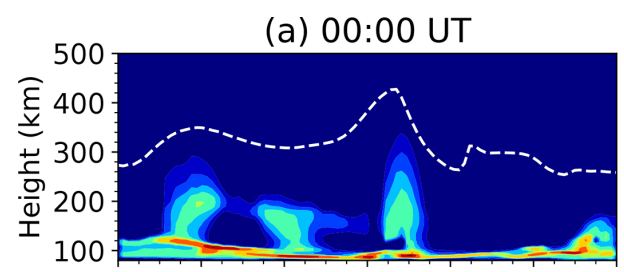

(c) 12:00 UT

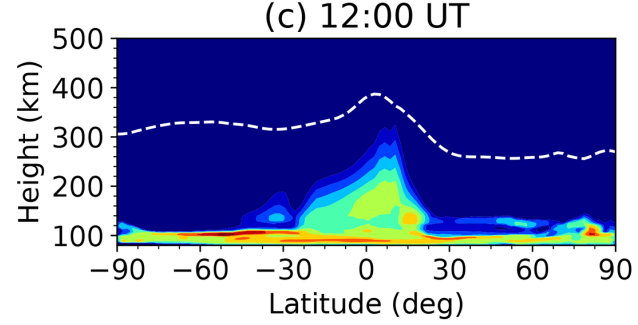

(e)

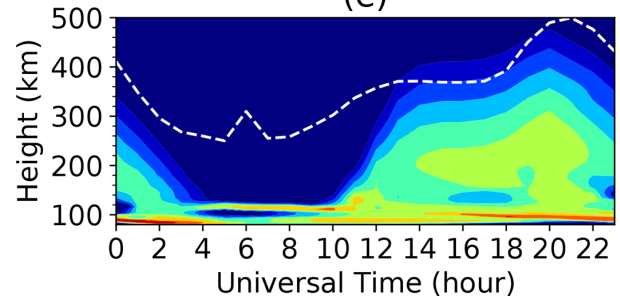

(b) 06:00 UT

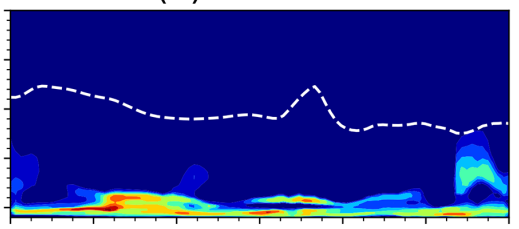

(d) 18:00 UT

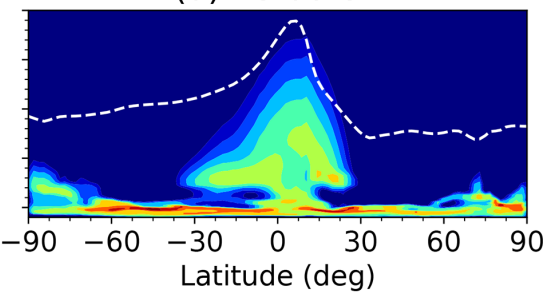

0.00 .51 .01 .52 .02 .53 .03 .54 .0

$\mathrm{Mg}^{+}$Number Density $\left[\log 10 \mathrm{~cm}^{-3}\right]$

Figure 4. (a-d) $\mathrm{Mg}^{+}$density as a function of latitude and altitude at the December solstice and longitude $0^{\circ}$, at four universal times (local times): 00:00, 06:00, 12:00, and 18:00 UT. (e) $\mathrm{Mg}^{+}$density over $\left(12^{\circ} \mathrm{N}, 0^{\circ}\right)$ as a function of universal time and altitude. The dashed white lines denote $\mathrm{hmF}_{2}$.

transported symmetrically to both sides of the geomagnetic equator, which is closer to the scenario proposed by Cai et al. (2019).

\section{3 $\mathrm{Fe}$ and $\mathrm{Fe}^{+}$vertical profile comparison}

In order to demonstrate the effect of electrodynamical transport on the metals, a standard simulation without metal ion transport was performed (termed the control run). Figure 5 shows the $\mathrm{Fe}^{+}$and $\mathrm{Fe}$ vertical profiles for the ion transport run (solid lines) and control run (dotted/dashed lines) at the equinoxes and solstices. Three geographic latitudes at a longitude of $180^{\circ}$ are chosen for comparison: $0^{\circ}$ for the magnetic equator, $20^{\circ} \mathrm{S}$ for the subtropical region corresponding to the fountain effect downward drift, and $45^{\circ} \mathrm{S}$ for the middle latitudes corresponding to the summertime peak altitude. Without the ion transport (the control run), both Fe and $\mathrm{Fe}^{+}$exhibit roughly Gaussian-shaped layers, with peak heights between 90 and $100 \mathrm{~km}$ (dotted/dashed lines). When ion transport is turned on, the vertical profiles of $\mathrm{Fe}^{+}$vary depending on latitude and season. For instance, $\mathrm{Fe}^{+}$near the equator is always transported to a higher altitude (blue lines), consistent with the fountain effect in the dip equator region. However, ions at subtropical $\left(20^{\circ} \mathrm{S}\right)$ (orange lines) and middle $\left(45^{\circ} \mathrm{S}\right)$ latitudes (green lines) exhibit quite different transport motions. At the December solstice at midnight, $\mathrm{Fe}^{+}$is transported to a high level ( $\sim 1 \mathrm{~cm}^{-3}$ at $\left.200-300 \mathrm{~km}\right)$ at mid- dle and subtropical latitudes, which is related to the dominant upward drift velocity due to neutral wind (not shown). In other seasons, these ions can be transported both upward and downward, depending on the vertical ion velocity.

Since the neutral atoms are not directly transported by the electromagnetic field, they are influenced by ions through the recombination between ions and electrons. The last two panels in Fig. 5 illustrate the Fe atom distributions. In general, changes in $\mathrm{Fe}$ (at densities $>1 \mathrm{~cm}^{-3}$ ) do not appear to be synchronized with the upward transport of $\mathrm{Fe}^{+}$, so that the vertical distribution of $\mathrm{Fe}$ in the transport run is similar to that in the control run. However, there is an obvious increase in high-altitude $\mathrm{Fe}$ (i.e. above $\sim 140 \mathrm{~km}$ ) in the equatorial region (blue line), corresponding to the upward transport of ions; and at the December solstice around midnight, the $\mathrm{Fe}$ number density above $150 \mathrm{~km}$ is much higher than that in the control run at all southern latitudes.

\subsection{Effect of metal ion mass on transport}

Figure 6 compares the $\mathrm{Mg}^{+} / \mathrm{Fe}^{+}$ratio (left panels) and the $\mathrm{Mg}^{+} / \mathrm{Na}^{+}$ratio (right panels) as a function of height and latitude at the equinoxes and solstices. Note that changes in the ratios below $100 \mathrm{~km}$ are due to differences in the ionmolecule chemistries of the metals (Plane et al., 2015), which is not the focus here. There are several advantages in choosing these three metallic ions. First, $\mathrm{Fe}^{+}$is more than twice 

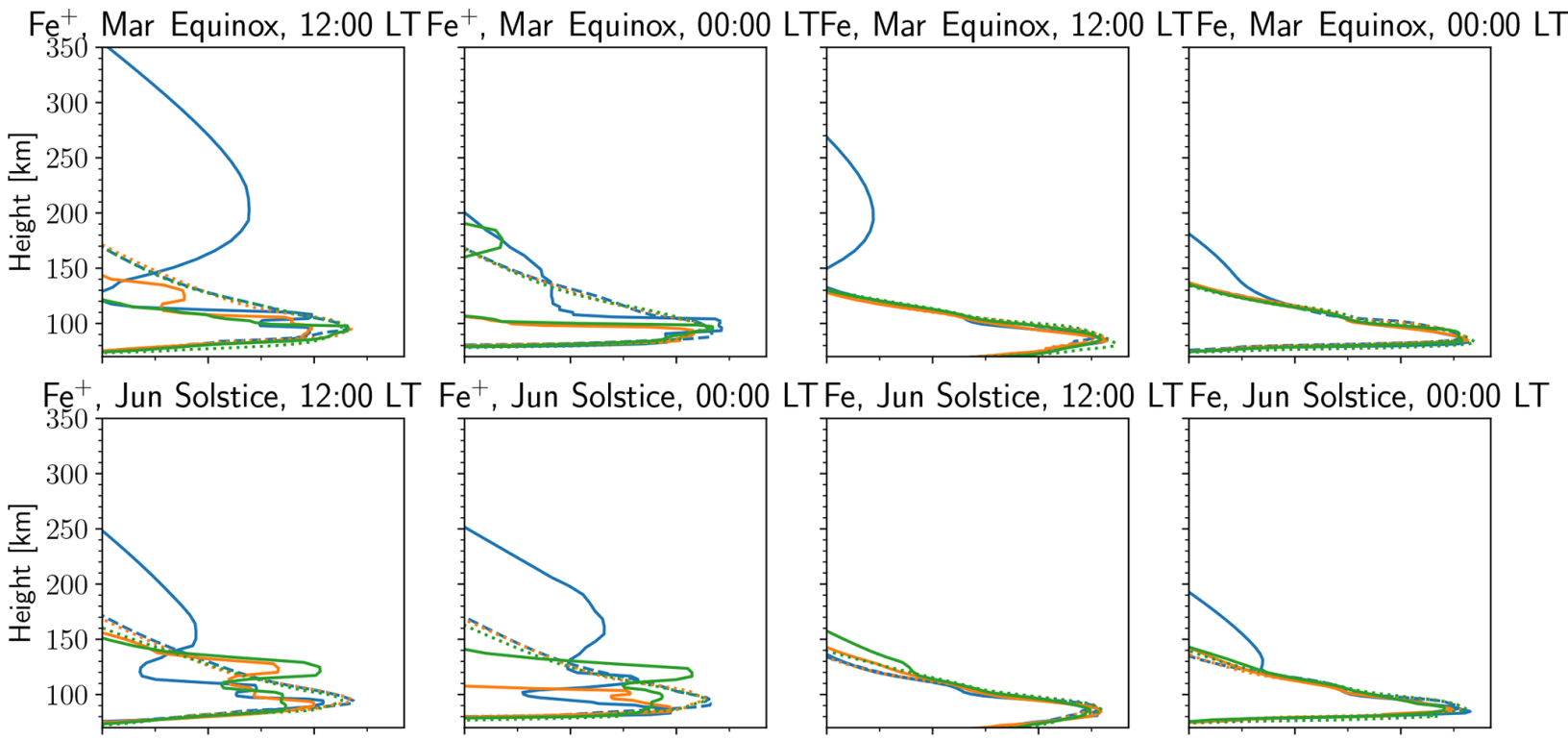

LTFe, Jun Solstice, 00:00 LT

$\mathrm{Fe}^{+}$, Sep Equinox, 12:00 LTFe ${ }^{+}$, Sep Equinox, 00:00
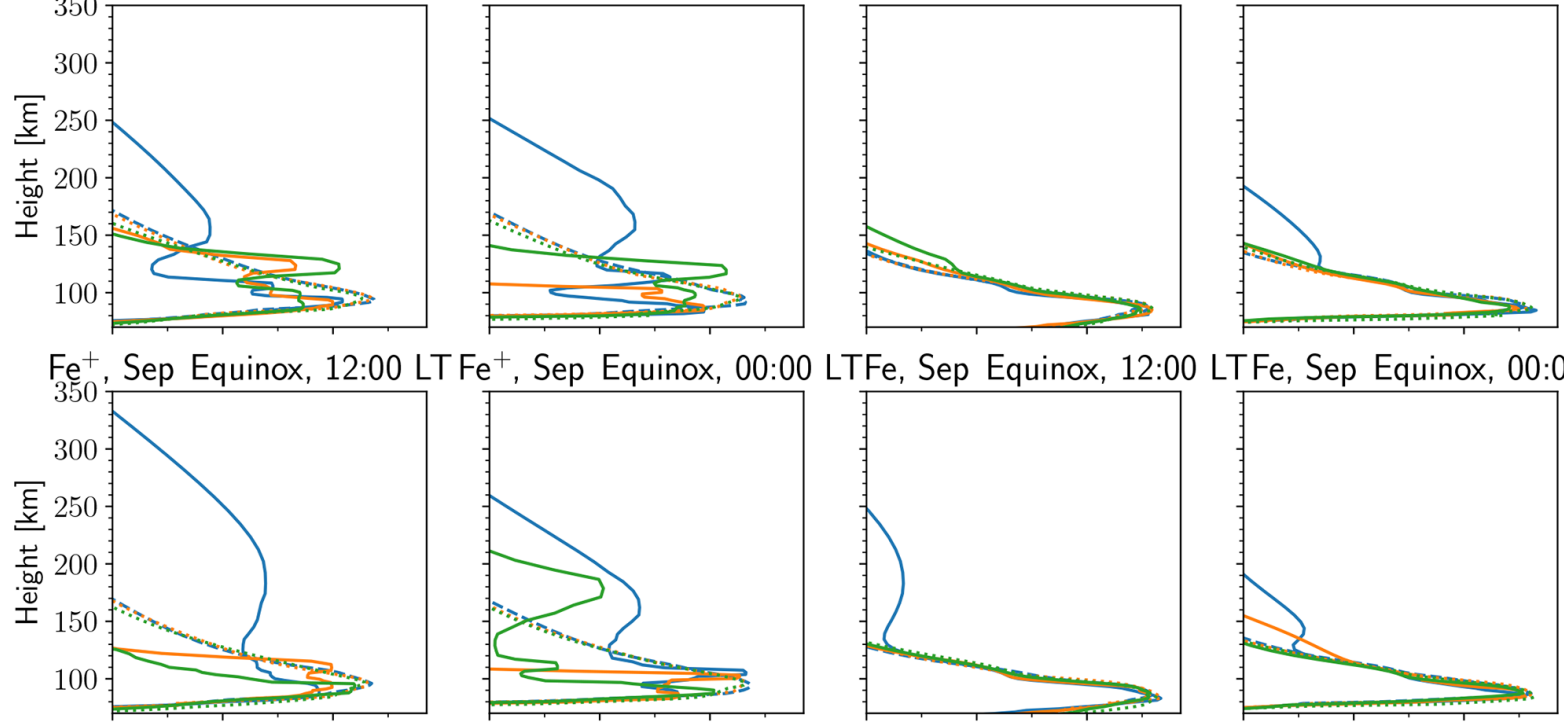

$\mathrm{Fe}^{+}$, Dec Solstice, 12:00 LT Fe ${ }^{+}$, Dec Solstice, 00:00
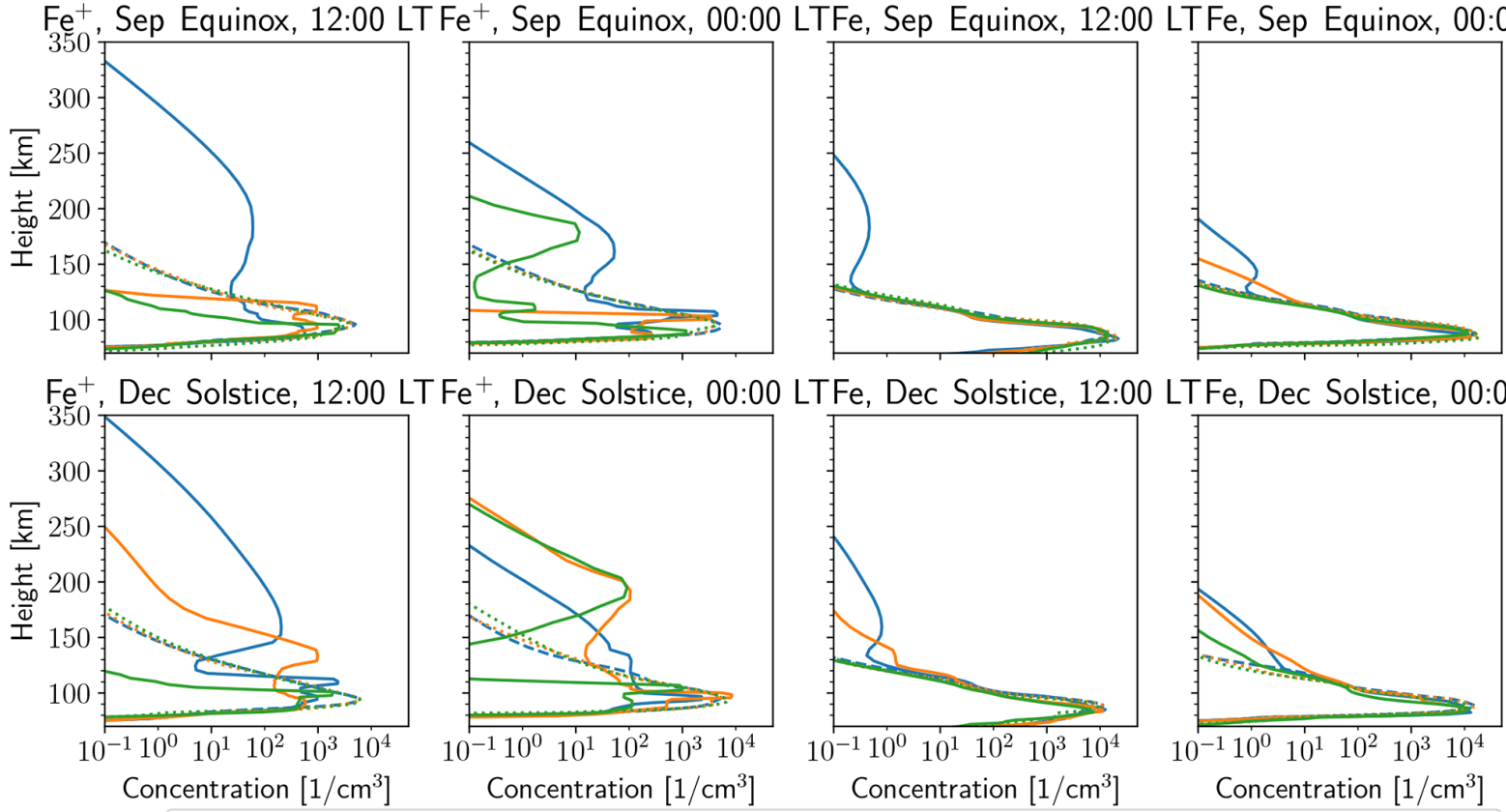

- $\left(180^{\circ}, 0^{\circ}\right)$ Transport Run

$\left(180^{\circ}, 20^{\circ} \mathrm{S}\right)$ Transport Run

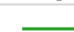

LTFe, Dec Solstice, 00:00 LT

---- $\left(180^{\circ}, 0^{\circ}\right)$ Control Run

......... $\left(180^{\circ}, 20^{\circ} \mathrm{S}\right)$

S) Control Run

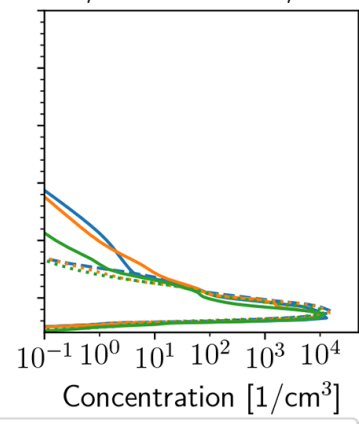

$\left(180^{\circ}, 45^{\circ} \mathrm{S}\right)$ Transport Run

$\left(180^{\circ}, 45^{\circ} \mathrm{S}\right)$ Control Run

Figure 5. Comparison of the vertical profiles of the $\mathrm{Fe}^{+}$(left two panels) and $\mathrm{Fe}$ (right two panels) number densities, for the control run (dotted/dashed lines) and the run with ion transport (solid lines) over selected geographic latitudes, at the equinoxes and solstices and midday (12:00 LT) and midnight (00:00 LT).

as heavy as $\mathrm{Mg}^{+}$. Second, $\mathrm{Fe}^{+}$is much heavier and $\mathrm{Mg}^{+}$is slightly lighter than the mean mass of air molecules in the E region. Third, $\mathrm{Na}^{+}$has a comparable mass with $\mathrm{Mg}^{+}$. As expected, the lighter ions are transported above $150 \mathrm{~km}$ more easily than the heavy $\mathrm{Fe}^{+}$, so that the $\mathrm{Mg}^{+} / \mathrm{Fe}^{+}$ratio increases from $\sim 1$ at $120 \mathrm{~km}$ to $>2$ above $150 \mathrm{~km}$ and to $>30$ above $300 \mathrm{~km}$. By the same token, the $\mathrm{Mg}^{+} / \mathrm{Na}^{+}$ratio shows very little change above $120 \mathrm{~km}$.
The zonally averaged $\mathrm{Fe}^{+} / \mathrm{Mg}^{+}$ratio below $200 \mathrm{~km}$ simulated by WACCM-X also accords with the limited available observations (Dymond et al., 2003; Kumar and Hanson, 1980), which showed that the average $\mathrm{Fe}^{+} / \mathrm{Mg}^{+}$ratio is around $1.5: 1$. The present study also simulates the extreme variability of the $\mathrm{Fe}^{+} / \mathrm{Mg}^{+}$ratio above $300 \mathrm{~km}$ (as low as $1: 50$ in Kumar and Hanson, 1980). However, the unexpectedly large $\mathrm{Fe}^{+} / \mathrm{Mg}^{+}$ratio $(\sim 10-50)$ reported by Dymond 

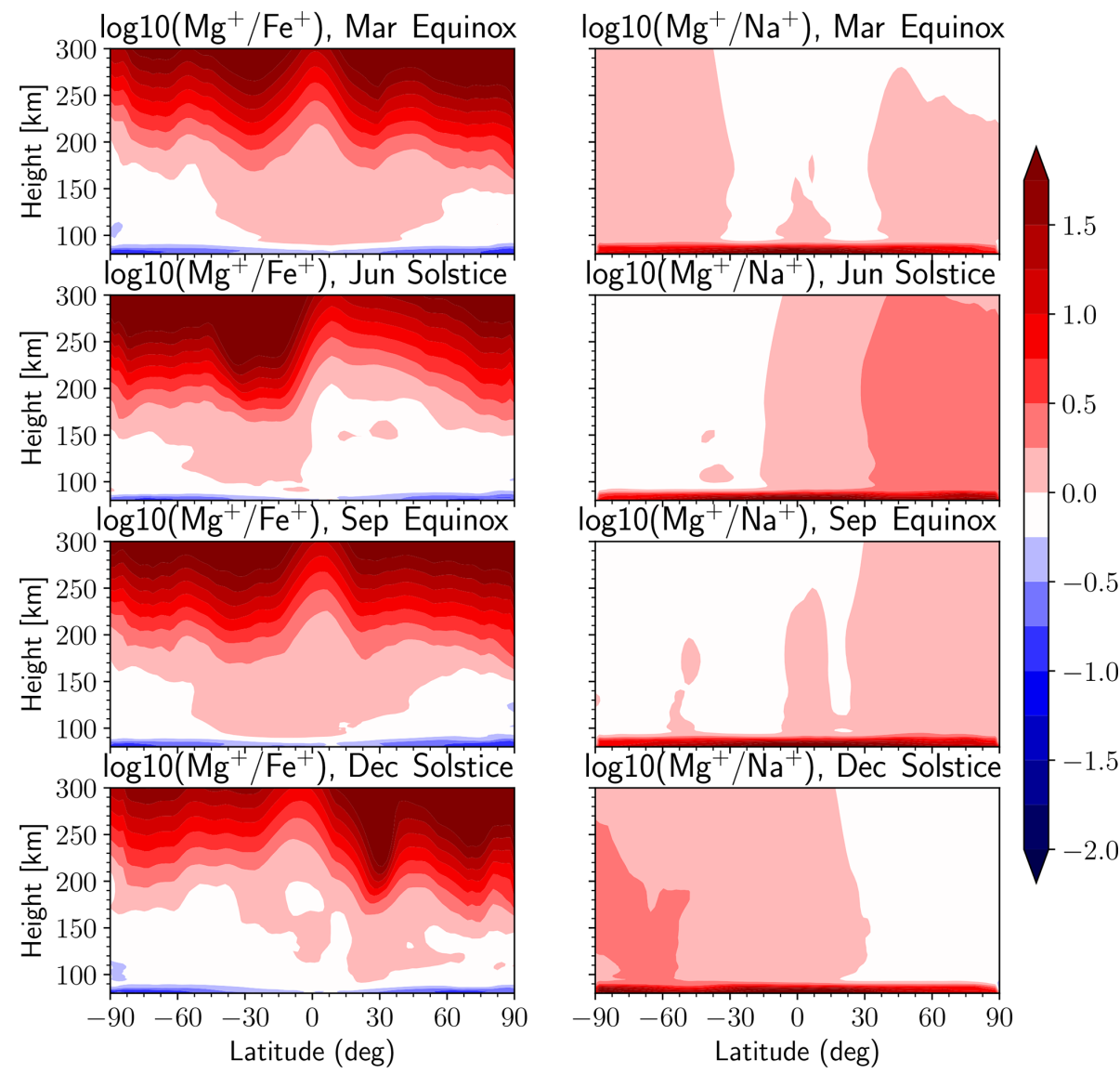

Figure 6. The zonally averaged $\mathrm{Mg}^{+} / \mathrm{Fe}^{+}$ratio (left panels) and $\mathrm{Mg}^{+} / \mathrm{Na}^{+}$ratio (right panels) versus height and latitude at the equinoxes and solstices.

et al. (2003) is only captured at a few points about $150 \mathrm{~km}$ in our model (not shown). Interestingly, the striking differences between distinct thermosphere-ionosphere $\mathrm{Fe}$ and diffuse thermosphere-ionosphere $\mathrm{Na}$ reported by Chu et al. (2020) are thought to be related to mass separation. There is no question that more observations are needed to confirm and validate these findings.

Figure 6 shows that whereas the $\mathrm{Mg}^{+} / \mathrm{Fe}^{+}$ratios (left panels) show relatively little latitudinal variation compared with the variation with altitude (mostly caused by the mass difference of the ions), the $\mathrm{Mg}^{+} / \mathrm{Na}^{+}$ratios (right panels) show marked interhemispheric differences at the solstice periods. The reason for this is the difference in the ion-molecule chemistry of $\mathrm{Na}^{+}$, compared with $\mathrm{Mg}^{+}$(and $\mathrm{Fe}^{+}$). The $\mathrm{Na}^{+}$ ion has a closed electronic shell (it is isoelectronic with the inert gas $\mathrm{Ne}$ ) and so does not react with $\mathrm{O}_{3}$, in contrast to $\mathrm{Mg}^{+}$and $\mathrm{Fe}^{+}$(Plane et al., 2015). Formation of $\mathrm{MgO}^{+}$by the fast reaction with $\mathrm{O}_{3}$ is the main route to neutralization of $\mathrm{Mg}^{+}$above $90 \mathrm{~km}$ (Whalley et al., 2011). During summer at mid-latitudes to high latitudes $\left(>30^{\circ}\right), \mathrm{O}_{3}$ above $90 \mathrm{~km}$ is heavily depleted through a combination of longer diurnal photolysis and reaction with the elevated levels of $\mathrm{H}$ produced from $\mathrm{H}_{2} \mathrm{O}$ which upwells over the summer pole (Plane et al., 2015). In contrast, the $\mathrm{O}_{3}$ density in the lower thermosphere is more than an order of magnitude higher in the winter polar vortex. The result is that lower thermospheric $\mathrm{Mg}^{+}$ions at latitudes higher than $\sim 30^{\circ}$ are relatively longlived in summer and can be transported vertically throughout the thermosphere. This leads to the higher $\mathrm{Mg}^{+} / \mathrm{Na}^{+}$ ratios in the summer hemisphere, as shown in Fig. 6. The converse operates at latitudes higher than $30^{\circ}$ in the winter hemisphere, where the relatively high $\mathrm{O}_{3}$ tends to neutralize lower thermospheric $\mathrm{Mg}^{+}$. Because $\mathrm{Na}^{+}$and $\mathrm{Mg}^{+}$have very similar masses, their ratios above $100 \mathrm{~km}$ are fairly constant with height.

\subsection{Effect of $\mathrm{NO}^{+}$and $\mathrm{O}_{2}^{+}$transport}

Figures 7 and 8 compare the distribution of metal ions from two simulations, one with the transport of all ions (hereafter TA) and the other with $\mathrm{NO}^{+}$and $\mathrm{O}_{2}^{+}$in chemical equilibrium (hereafter $\mathrm{CE}$ ). Note that the simulation results presented herein investigate the potential impacts of the transport of two major molecular ions on the distribution of metallic ions and do not provide a comprehensive review of all possible effects. 
(a)

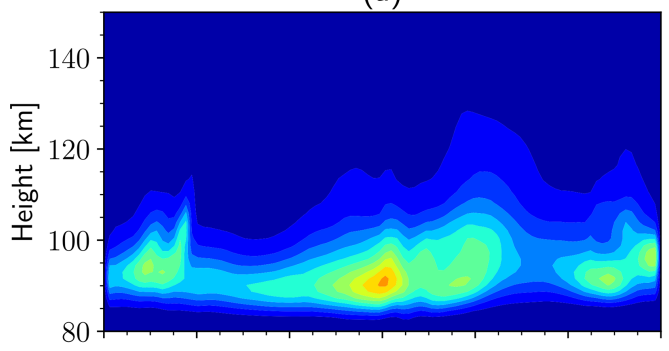

(b)

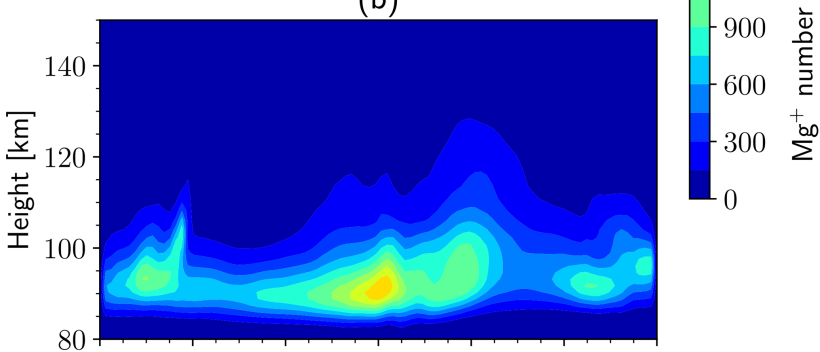

(c)

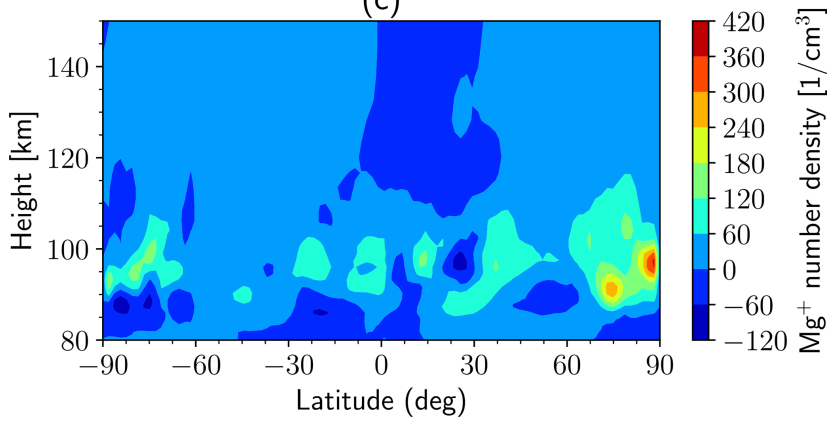

Figure 7. The monthly and zonal mean of the $\mathrm{Mg}^{+}$number density in June from (a) the TA simulation and (b) the CE simulation. (c) The difference between the TA and CE simulations.

Figure 7 shows the monthly mean density of $\mathrm{Mg}^{+}$as a function of latitude and altitude in June for the TA (Fig. 7a) and CE (Fig. 7b) simulations, along with their difference (Fig. 7c), where the monthly mean data are zonally averaged. In general, there is a good correspondence between the two simulations in terms of the latitude-altitudinal distribution of the monthly mean $\mathrm{Mg}^{+}$density. As seen in Fig. 7c, the peak density in CE simulation is generally a little higher than that in the TA simulation, especially in the high latitudes of the Southern Hemisphere. Figure 8 compares the diurnal variation of $\mathrm{Mg}^{+}$in the two simulations. Both cases simulate the significant fountain effect, which was discussed in Sect. 3.2. With the transport of major molecular ions, the peak height of the metal layer after midnight is higher. As discussed by Plane et al. (2015), the charge transfer of neutral metal atoms with $\mathrm{NO}^{+}$and $\mathrm{O}_{2}^{+}$is the major sources of metallic ions in the $\mathrm{E}$ region. Due to the very short lifetimes of $\mathrm{NO}^{+}$and $\mathrm{O}_{2}^{+}$during daytime, the transport of these molecular ions between model grid boxes has little effect on the metallic ions. In contrast, the reduced densities of the molecular ions (and electrons) at night mean that their increased lifetimes become comparable to transport time step. Additional metallic ions are therefore produced via charge transfer with the downward transport of $\mathrm{NO}^{+}$and $\mathrm{O}_{2}^{+}$at night in the TA simulation.

\section{Conclusions}

The WACCM-X high-altitude chemistry-climate model has been extended to incorporate the full life cycle of multiple meteoric metal ions and atoms $(\mathrm{Mg}, \mathrm{Na}$, and $\mathrm{Fe}$, currently). A major advantage of WACCM-X is the self-consistent treatment of dynamics and electrodynamics, allowing us to quantitatively investigate the global distribution of metal ions and the formation mechanisms of thermospheric metal layers. The present study explores, for the first time, the seasonal variations of thermospheric metal ions by including global metal ion transport in the $\mathrm{E}$ and $\mathrm{F}$ regions.

There are a number of interesting findings: (1) a clear seasonal cycle is found in the monthly averaged global distributions of $\mathrm{Mg}^{+}$, in good agreement with the SCIAMACHY measurements (Langowski et al., 2015), although the peak height and peak density are about $5 \mathrm{~km}$ and $35 \%$ lower than the observations, respectively. (2) Uplift of metal ions in the summer hemisphere at mid-latitudes $\left(\sim 40^{\circ} \pm 10^{\circ}\right)$, driven by the vertical ion velocity due to the neutral wind, appears to explain the summer peak occurrence of lower thermospheric neutral $\mathrm{Na}$ layers observed by mid-latitude lidars (Wang et al., 2012; Dou et al., 2013; Yuan et al., 2014; Xun et al., 2020). (3) Upward transport of metallic ions by $E \times B$ forcing is generally consistent with the fountain effect. (4) The formation of thermospheric neutral metal layers is strongly influenced by the upward transport of ions, since metallic atoms and ions are coupled by relatively fast reactions in the lower thermosphere (Plane et al., 2015). (5) A pronounced mass separation of $\mathrm{Fe}^{+}$with the two lighter ions, $\mathrm{Mg}^{+}$and $\mathrm{Na}^{+}$, is demonstrated above $150 \mathrm{~km}$, with the ratio between the lighter ions $\left(\mathrm{Mg}^{+}\right.$and $\left.\mathrm{Na}^{+}\right)$and heavier ions $\left(\mathrm{Fe}^{+}\right)$increasing with height by more than a factor of 2 above $150 \mathrm{~km}$. More satellite observations of the $\mathrm{Mg}^{+} / \mathrm{Fe}^{+}$ratio are needed to test this prediction. (6) The role of $\mathrm{NO}^{+}$and $\mathrm{O}_{2}^{+}$transport in the distribution of metal ions in the model is examined by comparing the two simulation results. It is found that they have little effect on the monthly means of metal ions but affect the peak heights of metallic ions in the descending phase of the fountain effect.

Previous research has established that thermospheric neutral metal layers are modulated by dynamics (e.g. gravity waves, atmospheric tides) (e.g. Chu et al., 2011; Xue et al., 2013; Liu et al., 2016; Cai et al., 2017; Qiu et al., 2016; Chu et al., 2020). In the future, this new version of WACCM$\mathrm{X}$ can be used to better investigate the effect of lower atmospheric dynamical processes on the formation of thermospheric neutral metal layers using the "specified dynamics" version of the model (SD-WACCM-X). 
(a)

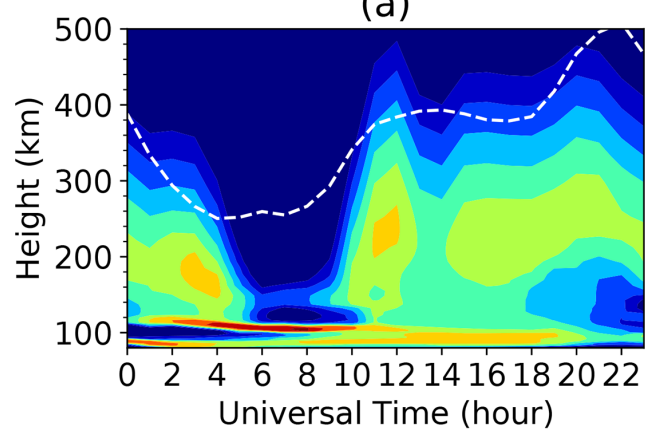

(b)

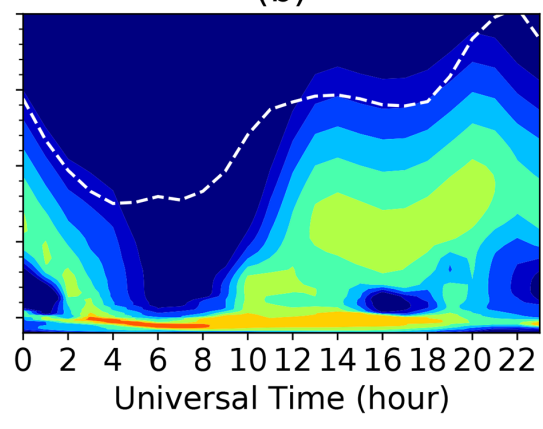

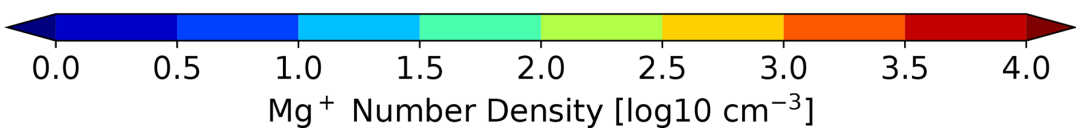

Figure 8. $\mathrm{Mg}^{+}$density over $\left(12^{\circ} \mathrm{N}, 0^{\circ}\right.$, near the dip equator) as a function of universal time and altitude at June solstice. The dashed lines denote hmF2. (a) for the TA simulation and (b) for the CE simulation.

Code and data availability. The WACCMX model output has been archived at the National Space Science Data Center, National Science \& Technology Infrastructure of China (https://doi.org/10.12176/01.60.00002-V01, University of Science and Technology of China, 2021), and the simulation data sets used in this study are freely available from the NSSDC Space Science Article Data Repository (https://doi.org/10.12176/01.99.00212, Wu et al., 2021). As a part of CESM2, WACCM-X is available at http: //www.cesm.ucar.edu/models/cesm2/ (last access: 8 October 2021, UCAR, 2021).

Author contributions. JW, WF, HLL, and JMCP designed the simulations and wrote the manuscript. XX and DRM contributed to the discussion and explanation of model simulations. All authors discussed the results and commented on the manuscript at all stages.

Competing interests. The authors declare that they have no conflict of interest.

Disclaimer. Publisher's note: Copernicus Publications remains neutral with regard to jurisdictional claims in published maps and institutional affiliations.

Acknowledgements. The numerical calculations in this paper were in part undertaken on the supercomputing system in the Supercomputing Center of University of Science and Technology of China and ARC3, part of the high-performance computing facilities at the University of Leeds.

Financial support. This work was supported by the B-type Strategic Priority Program of the Chinese Academy of Sciences (grant no. XDB41000000), the National Natural Science Foundation of China (grant nos. 42074181, 42125402, 41831071, 41804147, and
41704148), the Project of Stable Support for Youth Team in Basic Research Field, CAS (grant no. YSBR-018), and the Open Research Project of Large Research Infrastructures of CAS "Study on the interaction between low/mid-latitude atmosphere and ionosphere based on the Chinese Meridian Project". Jianfei Wu was funded by the Joint Open Fund of Mengcheng National Geophysical Observatory (grant no. MENGO-202008). Wuhu Feng and John Maurice Campbell Plane were funded by the European Research Council CODITA project (grant no. 291332). Han-Li Liu acknowledges partial support by NSF OPP (grant no. 1443726). The National Center for Atmospheric Research is a major facility sponsored by the National Science Foundation under Cooperative Agreement No. 1852977.

Review statement. This paper was edited by Franz-Josef Lübken and reviewed by three anonymous referees.

\section{References}

Banks, P. and Kockarts, G. (Eds.): Chapter 19 - Plasma Transport, in: Aeronomy, Academic Press, New York, 152-168, https://doi.org/10.1016/B978-0-12-077802-7.50011-7, 1973.

Bones, D. L., Plane, J. M. C., and Feng, W.: Dissociative Recombination of $\mathrm{FeO}^{+}$with Electrons: Implications for Plasma Layers in the Ionosphere, J. Phys. Chem. A, 120, 1369-1376, https://doi.org/10.1021/acs.jpca.5b04947, 2016.

Boris, J., Landsberg, A., Oran, E., and Gardner, J.: LCPFCTA Flux-Corrected Transport Algorithm for Solving Generalized Continuity Equations, Naval Research Lab Washington DC, NRL Memorandum Report, 93-7192, 1993.

Cai, X., Yuan, T., and Eccles, J. V.: A Numerical Investigation on Tidal and Gravity Wave Contributions to the Summer Time Na Variations in the Midlatitude E Region, J. Geophys. Res.-Space, 122, 10577-10595, https://doi.org/10.1002/2016JA023764, 2017.

Cai, X., Yuan, T., Eccles, J. V., Pedatella, N. M., Xi, X., Ban, C., and Liu, A. Z.: A Numerical Investigation on the Variation of 
Sodium Ion and Observed Thermospheric Sodium Layer at Cerro Pachón, Chile During Equinox, J. Geophys. Res.-Space, 124, 10395-10414, https://doi.org/10.1029/2018JA025927, 2019.

Carrillo-Sánchez, J. D., Gómez-Martín, J. C., Bones, D. L., Nesvorný, D., Pokorný, P., Benna, M., Flynn, G. J., and Plane, J. M.: Cosmic dust fluxes in the atmospheres of Earth, Mars, and Venus, Icarus, 335, 113395, https://doi.org/10.1016/j.icarus.2019.113395, 2020.

Carter, L. N. and Forbes, J. M.: Global transport and localized layering of metallic ions in the upper atmospherer, Ann. Geophys., 17, 190-209, https://doi.org/10.1007/s00585-999-0190-6, 1999.

Chu, X. and Yu, Z.: Formation mechanisms of neutral Fe layers in the thermosphere at Antarctica studied with a thermosphereionosphere $\mathrm{Fe} / \mathrm{Fe}^{+}$(TIFe) model, J. Geophys. Res.-Space, 122, 6812-6848, https://doi.org/10.1002/2016JA023773, 2017.

Chu, X., Yu, Z., Gardner, C. S., Chen, C., and Fong, W.: Lidar observations of neutral $\mathrm{Fe}$ layers and fast gravity waves in the thermosphere $(110-155 \mathrm{~km})$ at McMurdo $\left(77.8^{\circ} \mathrm{S}, 166.7^{\circ} \mathrm{E}\right)$, Antarctica, Geophys. Res. Lett., 38, L23807, https://doi.org/10.1029/2011GL050016, 2011.

Chu, X., Nishimura, Y., Xu, Z., Yu, Z., Plane, J. M. C., Gardner, C. S., and Ogawa, Y.: First Simultaneous Lidar Observations of Thermosphere-Ionosphere $\mathrm{Fe}$ and $\mathrm{Na}$ (TIFe and TINa) Layers at McMurdo $\left(77.84^{\circ} \mathrm{S}, 166.67^{\circ} \mathrm{E}\right)$, Antarctica With Concurrent Measurements of Aurora Activity, Enhanced Ionization Layers, and Converging Electric Field, Geophys. Res. Lett., 47, e2020GL090181, https://doi.org/10.1029/2020GL090181, 2020.

Dou, X. K., Qiu, S. C., Xue, X. H., Chen, T. D., and Ning, B. Q.: Sporadic and thermospheric enhanced sodium layers observed by a lidar chain over China, J. Geophys. Res.-Space, 118, 66276643, https://doi.org/10.1002/JGRA.50579, 2013.

Dymond, K. F., Wolfram, K. D., Budzien, S. A., Nicholas, A. C., McCoy, R. P., and Thomas, R. J.: Middle ultraviolet emission from ionized iron, Geophys. Res. Lett., 30, 1003, https://doi.org/10.1029/2002GL015060, 2003.

Feng, W. H., Marsh, D. R., Chipperfield, M. P., Janches, D., Hoffner, J., Yi, F., and Plane, J. M. C.: A global atmospheric model of meteoric iron, J. Geophys. Res.-Atmos., 118, 94569474, 2013.

Friedman, J. S., Chu, X., Brum, C. G. M., and Lu, X.: Observation of a thermospheric descending layer of neutral K over Arecibo, J. Atmos. Sol.-Terr. Phy., 104, 253-259, https://doi.org/10.1016/j.jastp.2013.03.002, 2013.

Gao, Q., Chu, X., Xue, X., Dou, X., Chen, T., and Chen, J.: Lidar observations of thermospheric $\mathrm{Na}$ layers up to $170 \mathrm{~km}$ with a descending tidal phase at Lijiang $\left(26.7^{\circ} \mathrm{N}\right.$, $100.0^{\circ}$ E), China, J. Geophys. Res.-Space, 120, 9213-9220, https://doi.org/10.1002/2015JA021808, 2015.

Huba, J. D., Krall, J., and Drob, D.: Global Ionospheric Metal Ion Transport With SAMI3, Geophys. Res. Lett., 46, 7937-7944, https://doi.org/10.1029/2019GL083583, 2019.

Hurrell, J. W., Holland, M. M., Gent, P. R., Ghan, S., Kay, J. E., Kushner, P. J., Lamarque, J.-F., Large, W. G., Lawrence, D., Lindsay, K., Lipscomb, W. H., Long, M. C., Mahowald, N., Marsh, D. R., Neale, R. B., Rasch, P., Vavrus, S., Vertenstein, M., Bader, D., Collins, W. D., Hack, J. J., Kiehl, J., and Marshall, S.: The Community Earth System Model: A Framework for Collaborative Research, B. Am. Meteorol. Soc., 94, 1339-1360, https://doi.org/10.1175/BAMS-D-12-00121.1, 2013.
Joiner, J. and Aikin, A. C.: Temporal and spatial variations in upper atmospheric $\mathrm{Mg}^{+}$, J. Geophys. Res.-Space, 101, 5239-5249, https://doi.org/10.1029/95JA03517, 1996.

Kelley, M.: The Earth's Ionosphere: Plasma Physics and Electrodynamics, 2nd edn., Elsevier, Academic Press, London, UK, 2009.

Kumar, S. and Hanson, W. B.: The morphology of metallic ions in the upper atmosphere, J. Geophys. Res., 85, 6783-6801, https://doi.org/10.1029/JA085iA12p06783, 1980.

Langowski, M. P., von Savigny, C., Burrows, J. P., Feng, W., Plane, J. M. C., Marsh, D. R., Janches, D., Sinnhuber, M., Aikin, A. C., and Liebing, P.: Global investigation of the $\mathrm{Mg}$ atom and ion layers using SCIAMACHY/Envisat observations between 70 and $150 \mathrm{~km}$ altitude and WACCM-Mg model results, Atmos. Chem. Phys., 15, 273-295, https://doi.org/10.5194/acp15-273-2015, 2015.

Layzer, D.: Theory of Midlatitude Sporadic E, Radio Sci., 7, 385395, https://doi.org/10.1029/RS007i003p00385, 1972.

Liu, A. Z., Guo, Y., Vargas, F., and Swenson, G. R.: First measurement of horizontal wind and temperature in the lower thermosphere $(105-140 \mathrm{~km})$ with a Na Lidar at Andes Lidar Observatory, Geophys. Res. Lett., 43, 2374-2380, https://doi.org/10.1002/2016GL068461, 2016.

Liu, H., Foster, B. T., Hagan, M. E., McInerney, J. M., Maute, A., Qian, L., Richmond, A. D., Roble, R. G., Solomon, S. C., Garcia, R. R., Kinnison, D., Marsh, D. R., Smith, A. K., Richter, J., Sassi, F., and Oberheide, J.: Thermosphere extension of the Whole Atmosphere Community Climate Model, J. Geophys. Res.-Space, 115, A12302, https://doi.org/10.1029/2010JA015586, 2010.

Liu, H., Bardeen, C. G., Foster, B. T., Lauritzen, P., Liu, J., Lu, G., Marsh, D. R., Maute, A., McInerney, J. M., Pedatella, N. M., Qian, L., Richmond, A. D., Roble, R. G., Solomon, S. C., Vitt, F. M., and Wang, W.: Development and Validation of the Whole Atmosphere Community Climate Model With Thermosphere and Ionosphere Extension (WACCM-X 2.0), J. Adv. Model. Earth Sy., 10, 381-402, https://doi.org/10.1002/2017MS001232, 2018a.

Liu, J., Liu, H., Wang, W., Burns, A. G., Wu, Q., Gan, Q., Solomon, S. C., Marsh, D. R., Qian, L., Lu, G., Pedatella, N. M., McInerney, J. M., Russell, J. M., and Schreiner, W. S.: First Results From the Ionospheric Extension of WACCM-X During the Deep Solar Minimum Year of 2008, J. Geophys. Res.-Space, 123, 1534-1553, https://doi.org/10.1002/2017JA025010, 2018b.

Marsh, D. R., Janches, D., Feng, W. H., and Plane, J. M. C.: A global model of meteoric sodium, J. Geophys. Res.-Atmos., 118, 11442-11452, 2013a.

Marsh, D. R., Mills, M. J., Kinnison, D. E., Lamarque, J. F., Calvo, N., and Polvani, L. M.: Climate Change from 1850 to 2005 Simulated in CESM1(WACCM), J. Climate, 26, 73727391, https://doi.org/10.1175/JCLI-D-12-00558.1, 2013b.

Narcisi, R. S.: Processes associated with metal-ion layers in the E region of the ionosphere, Space Research, 8, 360-369, 1968.

Neale, R. B., Richter, J., Park, S., Lauritzen, P. H., Vavrus, S. J., Rasch, P. J., and Zhang, M. H.: The Mean Climate of the Community Atmosphere Model (CAM4) in Forced SST and Fully Coupled Experiments, J. Climate, 26, 5150-5168, https://doi.org/10.1175/JCLI-D-12-00236.1, 2013.

Pi, X. Q., Mannucci, A. J., Iijima, B. A., Wilson, B. D., Komjathy, A., Runge, T. F., and Akopian, V.: Assimilative Modeling 
of Ionospheric Disturbances with FORMOSAT-3/COSMIC and Ground-Based GPS Measurements, Terr. Atmos. Ocean. Sci., 20, 273-285, https://doi.org/10.3319/Tao.2008.01.04.01(F3c), 2009.

Plane, J. M. C., Feng, W., and Dawkins, E. C.: The mesosphere and metals: chemistry and changes, Chem. Rev., 115, 4497-541, https://doi.org/10.1021/cr500501m, 2015.

Qiu, S. C., Tang, Y. H., Jia, M. J., Xue, X. H., Dou, X. K., Li, T., and Wang, Y. H.: A review of latitudinal characteristics of sporadic sodium layers, including new results from the Chinese Meridian Project, Earth-Sci. Rev., 162, 83-106, https://doi.org/10.1016/j.earscirev.2016.07.004, 2016.

Schunk, R. W. and Nagy, A. F.: Simplified Transport Equations, Cambridge Atmospheric and Space Science Series, Cambridge University Press, Cambridge, U.K., 104-147, https://doi.org/10.1017/CBO9780511551772.005, 2000.

UCAR: CESM2 model, UCAR [code], available at: http://www. cesm.ucar.edu/models/cesm2/, last access: 8 October 2021.

University of Science and Technology of China: Atmospheric Metal Data Simulated by WACCMX model repository, National Space Science Data Center [data set], https://doi.org/10.12176/01.60.00002-V01, 2021.

Viehl, T. P., Plane, J. M. C., Feng, W., and Höffner, J.: The photolysis of $\mathrm{FeOH}$ and its effect on the bottomside of the mesospheric Fe layer, Geophys. Res. Lett., 43, 1373-1381, https://doi.org/10.1002/2015GL067241, 2016.

Wang, J., Yang, Y., Cheng, X., Yang, G., Song, S., and Gong, S.: Double sodium layers observation over Beijing, China, Geophys. Res. Lett., 39, L15801, https://doi.org/10.1029/2012GL052134, 2012.

Whalley, C. L., Martín, J. C. G., Wright, T. G., and Plane, J. M. C.: A kinetic study of $\mathrm{Mg}^{+}$and $\mathrm{Mg}$-containing ions reacting with $\mathrm{O}_{3}, \mathrm{O}_{2}, \mathrm{~N}_{2}, \mathrm{CO}_{2}, \mathrm{~N}_{2} \mathrm{O}$ and $\mathrm{H}_{2} \mathrm{O}$ : implications for magnesium ion chemistry in the upper atmosphere, Phys. Chem. Chem. Phys., 13, 6352-6364, https://doi.org/10.1039/C0CP02637A, 2011.
Wu, J., Feng, W., Liu, H.-L., Xue, X., Marsh, D. R., and Plane, J. M. C.: Simulation data of 'Self-consistent Global Transport of Metallic Ions with WACCM-X', V1, NSSDC Space Science Article Data Repository [data set], https://doi.org/10.12176/01.99.00212, 2021.

Xue, X. H., Dou, X. K., Lei, J., Chen, J. S., Ding, Z. H., Li, T., Gao, Q., Tang, W. W., Cheng, X. W., and Wei, K.: Lower thermospheric-enhanced sodium layers observed at low latitude and possible formation: Case studies, J. Geophys. Res.-Space, 118, 2409-2418, https://doi.org/10.1002/JGRA.50200, 2013.

Xun, Y., Yang, G., Wang, J., Du, L., Wang, Z., Jiao, J., Cheng, X., Li, F., and Zou, X.: The Comprehensive Study of Low Thermospheric Sodium Layers during the 24th Solar Cycle, Atmosphere, 11, 284, https://doi.org/10.3390/atmos11030284, 2020.

Yu, B., Xue, X., Scott, C. J., Wu, J., Yue, X., Feng, W., Chi, Y., Marsh, D. R., Liu, H., Dou, X., and Plane, J. M. C.: Interhemispheric transport of metallic ions within ionospheric sporadic $E$ layers by the lower thermospheric meridional circulation, Atmos. Chem. Phys., 21, 4219-4230, https://doi.org/10.5194/acp21-4219-2021, 2021.

Yuan, T., Wang, J., Cai, X., Sojka, J., Rice, D., Oberheide, J., and Criddle, N.: Investigation of the seasonal and local time variations of the high-altitude sporadic Na layer (Nas) formation and the associated midlatitude descending E layer (Es) in lower E region, J. Geophys. Res.-Space, 119, 5985-5999, https://doi.org/10.1002/2014JA019942, 2014. 